\title{
Male Patient Perceptions of HIV Stigma in Health Care Contexts
}

\author{
LANCE S. RINTAMAKI, Ph.D., ${ }^{1}$ ALLISON M. SCOTT, M.A., ${ }^{2}$ KAMA A. KOSENKO, Ph.D. ${ }^{2}$ \\ and ROBIN E. JENSEN, Ph.D. ${ }^{3}$
}

\begin{abstract}
Individuals living with HIV may have a heightened sensitivity to the behaviors of others that may signal bias or discrimination. Identifying and avoiding these potentially problematic behaviors may be especially important for service providers, such as health care personnel, who regularly interact with HIV-positive clientele. This study examines the experiences of 50 male American military veterans living with HIV and their perceptions of HIV stigma within health care contexts. Participants described a variety of behaviors performed by health care personnel that they perceived to be indicative of HIV stigma, ranging from ambiguous nonverbal cues (e.g., minimal eye contact) to blatant discrimination (e.g., physical abuse of HIV-positive patients). These findings extend previous research on HIV stigma in health care settings by (1) focusing on health care personnel's actual behaviors rather than their attitudes and beliefs about HIV-positive patients, (2) including patients' perceptions regarding the behaviors of both clinical and nonclinical health care personnel, and (3) identifying behaviors patients perceive as stigmatizing that are unique to health care contexts. Combined, these findings provide health care personnel a tangible list of behaviors that should either be avoided or further explained to HIV-positive patients, as they may be interpreted as stigmatizing.
\end{abstract}

\section{INTRODUCTION}

$\mathbf{R}$ ECENT ESTIMATES indicate that well over a million people are currently living with HIV in the United States. ${ }^{1}$ Although the introduction of antiretroviral treatments has dramatically increased the life span of those infected by the virus, ${ }^{2,3}$ progress in addressing the widespread social stigma surrounding HIV has lagged behind these biomedical advances. ${ }^{4,5}$ Despite public health efforts to educate the general public about HIV, a host of studies indicate that misconceptions of how the virus is transmitted and disparaging attitudes toward those infected with the virus are still prevalent. 5,6 Subsequently, people living with HIV often face ridicule, ostracism, and persecution in many forms, ranging from caustic social interactions to draconian legislative efforts designed to strip people living with HIV of their civil rights. ${ }^{7-13}$ In its extreme form, hostile expressions of HIV stigma have even driven people from their homes and led to acts of physical violence against them. ${ }^{8,14-16}$

The effects of HIV stigma on those living with the disease are significant and include adverse mental and physical health outcomes, such as elevated stress, depression, immune

\footnotetext{
${ }^{1}$ Department of Communication and Health Behavior, The State University of New York at Buffalo, Buffalo, New York.

${ }^{2}$ Department of Communication, University of Illinois at Urbana-Champaign, Urbana, Illinois.

${ }^{3}$ Department of Communication, Purdue University, West Lafayette, Indiana.
} 
suppression, and suicide. ${ }^{17-23}$ In addition, concern over being stigmatized can lead people to conceal their HIV status from others with whom they engage in risky behaviors, such as sexual activity or injection drug use. ${ }^{14,24-26}$ Similarly, to avoid discovery and potential stigmatization, people have even been found to forego their HIV medications in the presence of others, the consequences of which can be both viral resistance and clinical failure. ${ }^{27-29}$ Given its formidable range of social, psychological, and physical consequences, it is of no surprise that stigma as been labeled the most significant social and psychological challenge of the HIV experience. $^{30-32}$

One of the most troubling aspects of HIV stigma involves its prevalence and expression among health care personnel, who include all clinically and nonclinically employed individuals working in health care settings. Health care personnel have been instrumental in managing the HIV epidemic in the United States and abroad, serving both to treat people living with the virus and to educate the general public about HIV. However, health care staff are not immune to HIV stigma and some have, in fact, also been shown to openly report disparaging attitudes toward people living with the disease..$^{33-35}$ Such attitudes have been documented among a variety of health care personnel, including practicing physicians, medical students, nurses, and psychologists. ${ }^{36-38}$ Although such negative attitudes are shown to diminish as health care personnel gain experience working with HIV-positive patients, they may still persist even among those who have worked with such clientele for many years. ${ }^{39,40}$ Such attitudes have been linked to reluctance in health care personnel to interact with those living with the disease, in some cases leading to their refusal to provide care for HIV-positive patients. ${ }^{41-44}$

Beyond such blatant incidents as refusing to treat HIV-positive clientele, stigma may also be expressed by health care personnel through more subtle communication. Whether they are conscious of it or not, people frequently express their biased attitudes during social interaction, often through nonverbal gestures. ${ }^{45}$ In the context of HIV, relatively little research has examined expressions of stigma at such micro-social levels; however, the existing literature suggests that people living with HIV are attuned to subtle behaviors from others that alone may be explained away, but taken together cause people to feel stigmatized. ${ }^{46}$

Perhaps because of their experiences with bias and discrimination, or simply because of their mindfulness that they may be devalued by others, people who belong to stigmatized groups are shown to develop a heightened sensitivity to behaviors that may indicate the presence of prejudice or discrimination. ${ }^{47}$ Some research has revealed this type of sensitivity among people living with HIV and has shown that it may be especially acute when dealing with individuals on whom people must depend, such as health care personnel. ${ }^{46}$ Stigmatized people are more prone to interpret ambiguous and subtle behaviors as indicative of social stigma rather than the result of other equally plausible explanations. ${ }^{48-50}$ Subsequently, patients' heightened sensitivity to stigma may lead them to interpret ambiguous actions of health care personnel as stigmatizing, even when it is unclear that stigma is, in fact, being expressed. Regardless if these perceptions and interpretations of such behaviors are accurate, the impact on patients is no less significant. This suggests that even well-intentioned health care personnel may inadvertently exhibit behaviors that HIV-positive patients interpret negatively. ${ }^{51}$

Despite the obvious implications HIV stigma has for quality of care, surprisingly little research has been conducted in this area. The literature on HIV stigma includes only a handful of studies on HIV stigma in health care settings, with existing studies being limited in scope (e.g., focusing solely on one type of health care personnel, such as physicians or nurses) and emphasizing the antecedents of stigma (e.g., attitudes toward people living with HIV), rather than its behavioral manifestations. ${ }^{33,34,52,53}$ Exploration of patient's lived experiences and perceptions of HIV stigma in health care contexts is the next step in this line of inquiry. Such exploration is not only of great academic interest and pragmatic value, but may hold considerable legal consequence, as well. Identifying and avoiding such problematic behaviors may help health care personnel more quickly 
develop open and trusting relationships with HIV-positive patients. Avoidance of such behaviors may subsequently minimize the likelihood of malpractice lawsuits, because patients who like their care providers are less likely to sue than are those who experience troubled patient-provider relationships. ${ }^{54}$ Above all, avoidance of such behaviors will better fulfill the ethical obligations of health care personnel and improve clinical outcomes of their patients.

Exploration of patient's experiences and perceptions of stigmatizing behaviors among health care personnel includes identification of the more blatant and extreme expressions of HIV stigma among health care personnel, which to date have not been documented beyond occasional refusals to provide care for HIV-positive clientele. So, too, must it include the identification of the more subtle behaviors to which HIV-positive patients are acutely attuned. Assessment of patients' experiences encountering such behaviors must also include all types of health care personnel, not just clinical care providers. With these objectives in mind, the present study was conducted to explore patients' reported perceptions of and experiences with HIV stigma in health care contexts.

\section{MATERIALS AND METHODS}

As part of a larger study on coping with HIV stigma, American military veterans living with HIV were interviewed regarding their experiences with stigma and discrimination when interacting with health care personnel. A convenience sample of 50 participants was recruited through the infectious disease units at three Veterans Administration (VA) hospitals in a large city in the Midwestern United States. Participant recruitment entailed passive solicitation via handouts distributed onsite by infectious disease staff. Fliers were placed in common areas of the infectious disease clinic areas and waiting rooms at the various facilities (staff at these centers routinely provide information about such opportunities to their patients and actively requested the right to do so). Participants interested in taking part in the study contacted the primary investigator, who then scheduled them for either a focus group or one-on-one interview, depending on partic- ipants' preferences and availability. Participants received $\$ 25$ in remuneration for their involvement in either the focus group or the oneon-one interviews.

This study utilized a grounded theory approach during data collection, which involved reformulating and refining research questions as the study progressed to pursue promising lines of inquiry. ${ }^{55}$ This exploratory and hypotheses-generating process consisted of two stages. Stage 1 involved two semistructured focus group interviews $(n=3$ and 5, respectively) regarding participants' experiences with stigma and discrimination by health care providers; stage 2 involved one-on-one interviews $(n=42)$ on the same topics. This twotiered process was utilized to produce a data set that combined the synergy of focus groups with the depth of responses afforded by oneon-one interviews.

In stage 1, the lead author led two focus groups through a semistructured interview. The interview included questions regarding participants' experiences with the forms and effects of stigma and discrimination resulting from their HIV-positive status, including stigmatizing experiences with health care personnel (a total of 18 stigma-related questions were asked during the focus groups, 3 of which dealt directly with participants' perceptions of stigma among health care personnel). Probe and follow-up questions were included, when appropriate, to clarify issues and validate the interviewer's interpretations of responses. These focus groups lasted 120 minutes each. Based upon the findings from these focus groups, a more refined set of questions was developed to explore the problems participants experienced with health care personnel. These questions were then used during stage 2 of the study, which involved the primary investigator conducting in-depth, one-on-one interviews with participants regarding their stigma experiences. These one-on-one interviews lasted between 45 and 230 minutes (median $=70$ ). Digital recordings of the focus groups and interviews were transcribed verbatim and distributed to each member of the research team for coding.

Both the focus group and one-on-one interview transcripts were analyzed using latent content and constant comparative techniques. ${ }^{56}$ Coding included two stages of anal- 
ysis, with the first stage following the focus group interviews and the second stage following the one-on-one interviews. In stage 1 of analysis the primary investigator first reviewed the focus group data to identify focal themes among the participants' responses. This process helped identify and refine interview topics that required clarification or further exploration during the one-on-one interviews. Stage 2 of the analysis occurred after the one-on-one interviews were transcribed. The entire research team independently coded both the focus group and one-on-one interviews for focal themes, after which they convened to compare and compile their findings. Through consensus, the team constructed a detailed categorical system for describing the forms of problematic encounters participants experienced with health care personnel. Through this process, the research team codified an inventory of the ways in which participants experienced behaviors as stigmatizing and discriminatory when interacting with care providers and other personnel in health care contexts.

\section{RESULTS}

A total of 50 participants took part in either the focus groups or one-on-one interviews, ranging in age from 24 to 70 , with a mean age of 50 (standard deviation [SD] = 8.9). Twentysix $(52 \%)$ participants identified as African American, $17(34 \%)$ as Caucasian, $4(8 \%)$ as Latino, $1(2 \%)$ as Native American, $1(2 \%)$ as other, and $1(2 \%)$ who chose not to self-identify by race. Thirty-four (68\%) identified as heterosexual and 16 (32\%) as gay or bisexual. During the time of this study, no female veterans were receiving HIV care through the VA centers at which the study was advertised; subsequently, all study participants were male. Participants possessed varying degrees of formal education, with $6(12 \%)$ having not completed high school, 14 (28\%) having completed high school, 20 (40\%) having some college or technical/trade schooling, 6 (12\%) having a bachelors degree, and 4 (8\%) having either master's or doctoral degrees. Participants also reported a variety of occupational employments, with 12 (24\%) fully employed, 6 (12\%) unemployed, 26 $(52 \%)$ on disability, $5(10 \%)$ retired, and $1(2 \%)$ a full-time student. Time since diagnosis varied from one to 23 years, with a mean time of 12.8 years $(\mathrm{SD}=6$ years). Twenty-eight $(56 \%)$ of the participants had previously received an AIDS clinical diagnosis, although many had responded well to antiretroviral therapies and currently maintained CD4 counts well above 200.

Although several participants reported only positive experiences with health care providers, in which HIV stigma was noticeably absent, others reported encountering suspicious or explicitly stigmatizing behaviors in a variety of health care settings and across a broad range of health care personnel. Any behavior patients interpreted as conveying discomfort, ignorance, fear, contempt, or exclusion were coded as problematic and potentially stigmatizing. These behaviors are organized and presented below, which involve issues of demeanor, the provision of care, or combinations thereof. During events in which only stigmatizing demeanor was exhibited by health care personnel, treatment and other services were still perceived by patients to be fully and adequately provided. In contrast, stigmatizing events involving the provision of care involved denial or disruption of appropriate services for patients. In many instances, descriptions of problematic care provision also entailed stigmatizing demeanor on the part of health care personnel.

\section{Demeanor}

Participants identified a variety of encounters in which nonverbal cues from health care personnel sent ambiguous or explicitly problematic signals to patients. In particular, participants reported eye contact, proxemics (distance maintained between conversational partners), and paralanguage (vocal tone and inflection) as important indicators for interpreting others' feelings toward patients with HIV. The convergence of these nonverbals communicated what participants identified as various forms of negative affect, including irritation or anger, nervousness, or fear at having to work with HIV-positive clientele.

Eye contact. Participants described being mindful of the amount of eye contact provided 
them during health care interactions. In particular, a lack of eye contact was interpreted as possible discomfort with or dislike of HIV-positive patients. Evan describes such behavior during an encounter with a neurologist, who, he explained, "never looked me in the eye. I still don't know what his face looks like, which is not a crime, [but it] sends unfriendly signals. Or at least, cold signals." Although participants could not quantify how much eye contact was appropriate and sufficient to alleviate their perceptions of stigma, those who described such events felt confident the eye contact given by the health care personnel in question fell far below conventional expectations.

Paralanguage. Participants also described a heightened sensitivity to the vocal tones with which health care personnel spoke to patients. Clipped, flat, or brusque tones, in particular, where identified as indicating potential unease, dislike, or disdain of the HIV-positive patient. For instance, Kobe described how the tone of voice with which a nurse delivered his AIDS diagnosis left him feeling alienated and dismissed. He explained,

She made me feel low. It was just so callous and cold the way she said it. I think my viral load or CD4, one of 'em went below 200 and she said, "You have AIDS." And I said, "What?" The way she said, "Whenever you go below 200 you got AIDS." It was just the coldness in it-there wasn't no feeling. It's almost like a stone-faced warden or something. No concern, you know? I was like, "Wow." I felt awful.

Proxemics. Similarly, participants also described using the distance care providers placed between themselves and patients, or proxemics, as an indicator of providers' comfort with HIV clientele. Standing or positioning one's self close to the patient, such as within arm's reach, was considered a reassuring sign that the provider was unafraid of a person with HIV. Conversely, participants interpreted standing further away while interacting with a patient as an indication of fear or dislike on the part of the care provider. Participants reported encounters in which health care personnel maximized the space between themselves and their patients by doing such things as addressing them from across a room rather than approaching their bedsides. Gabriel described one such encounter in which, "The doctor was young, foreign. Maybe he was a med student. He went to the other side of the other patient's bed and talked loudly to me about having AIDS." Similar encounters involved care providers conversing with patients from hallways rather than coming into close proximity, such as an experience described by Max, in which, "[the doctor] wouldn't even come into the room."

Irritation/anger. Participants also identified specific affective states among health care personnel that HIV-positive patients may be prone to attribute to HIV stigma. For instance, when health care personnel expressed anger or irritation with or around HIV positive patients, the participants noted that they questioned if these negative emotions were due to the health care personnel having to deal directly (and unwillingly) with HIV-positive clientele. For instance, Tyler described having dealt with clerical staff who spoke to him in ways that he described as "standoffish." He further explained, "you get that feeling, that standoffish feeling, from the support services-from the clerks," which he attributed to his HIV-positive status. These problematic demeanors sometimes involved health care personnel expressing more than mere irritation, including what patients interpreted as full-fledged anger. Jacob's experience with an ambulance driver provides one such example, in which the participant attributed the health care provider's negative emotions to her having to work with an HIV-positive patient,

One time, my brother was washing dishes in the house. He had this big ceramic bowl and he dropped it. It bounced back and cut his wrists in a perfect football shape-took the skin right off. He couldn't have done a better job if he had a scalpel. He was bleeding profusely. He called 911 and the ambulance came, but he forgot to tell them right away that he had HIV. When he remembered to tell them, this ambulance driver was so pissed! It just blew me away. She took her gloves off, which were extremely bloody, and just threw them out onto the street. Left them there. And she wasn't exactly nice to him after that.

Nervousness/fear. Anger was not the only affective response participants described encountering amongst health care personnel that 
was attributed to HIV stigma. Participants noted such things as awkward glances, fidgeting, and agitated speech on the part of health care personnel as signs of nervousness around patients with HIV. Nervousness, though possibly attributable to a variety of factors, was credited to unreasonable fear of contagion when working with HIV-positive patients. For instance, Jerome described sensing a "nervous vibe" when seeking care from a dentist. He explains,

The dentist that was actually going to work on me, I felt like, the vibe that I got from him, the energy that I got from him, or at least, the demeanor that I got from him, was that he really didn't want to work on me or he wasn't comfortable working on me. And that was real disconcerting because I thought, "Where am I going to go to be able to get this done?"

Panic. Participants described inferring ignorance on the part of health care personnel when such events occurred. In particular, patients suspected that irrational fear of contagion and/or incomplete understanding of HIV's transmission routes were to blame for such behaviors. Sometimes this translated into care providers panicking when faced with the task of working with an HIV-positive patient. For instance, Roosevelt recounts an appointment with his dentist, who was informed of his patient's HIV status, but whose assistant was not. The assistant's reaction upon learning this information left a lasting impression with Roosevelt, who explained,

As I'm sitting there and we're talking, and [the assistant] comes running over. I could tell it was a big emergency. He says, "wait a minute!" and grabs the manila folder. Because he's writing it so large, I can tell what he's writing across the front of this manila folder on the side that I can't see, and he's writing the word "AIDS!"

Demeanor shifts. Such nonverbal and affective cues were particularly salient to patients when they were preceded by warmer, friendlier interactions. Participants explained that such noticeable shifts in demeanor often occurred after the patients' HIV status was revealed. Ahmad described one such example of incon- sistent nonverbal behavior, stating, "I went to this office and the lady asked what my disability was. When I told her, it seemed like her whole attitude changed." Carlos explained his perception of being judged during such encounters and his resulting frustration, stating,

It usually starts out with the front desk and the support staff, who are not educated. I mean, they should not care what I have, whether it's cancer, AIDS, or whatever. They should just be concerned that I get the best care I possibly can, you know? They have no right to make a judgment on me!

In several accounts of health care personnel's anger when dealing with HIV-positive patients, the patients failed at the onset of the encounter to inform the provider of their HIV status. However, patients during these encounters were often experiencing some form of duress, such as having been injured or suffering from another acute illness. Under these circumstances, Xavier explained how disclosing one's HIV status may not be on the patient's mind,

When you're in pain, that's not the first thing you're thinking about! That's not the first thing. When they picked me up, I was in pain and that was not the first thing I thought to tell them. It came to me a little bit later in the ambulance. But when you're in intense pain, HIV is not the first thing to come out of your mouth. They tell you it should be, but I was too focused on telling them where it hurt.

Excessive precautions. Perhaps as a result of these experiences of fearfulness among health care personnel, some participants described a heightened awareness of the safety precautions clinicians used when working with HIV-positive patients. In particular, they described being critical of what appeared to be excessive precautions or use of protective gear. For instance, Carlos described his trepidation over the protective gear his surgeons wore when they came to talk with him well in advance of his actual surgery. He recalled wondering the following questions,

Are the doctors dressed the way they're dressed because they're afraid they're going to get infected? They looked like they were ready for war. I mean, they had shields on-it was like looking at Roman gladiators! They were completely hermetically sealed. 
Jerome further explained the confusion HIVpositive patients feel when faced with such elaborate safety measures, by asking aloud, "Is this typical? Do they do this for everyone?" Unsure as to what constitutes standard procedure and what constitutes paranoid overprecaution, in the absence of explanation from care providers the patients were inclined to infer the latter.

Differential precautions. Another perceived problem regarding the use of protective gear involved clinicians using one set of precautions when working with some patients, then switching to other sets when working with HIV-positive patients. Although participants who witnessed such events applauded appropriate safety measures, they also felt the application of universal precautions when working with all types of patients would avoid the conspicuous altering of procedures that provokes suspicion and resentment from HIV-positive patients. Isaiah recounted one such situation when having his labs drawn by a phlebotomist,

Even today, there was a girl down there who took my blood. There was a guy in there before me whose blood she took-she didn't put on gloves. I never would have thought about that before, except I had somebody else there who had AIDS, who was saying, "Oh that's discrimination, because then they should do it [use consistent precautions] with everybody."

Labeling. Another set of problematic encounters some participants linked to fear and ignorance involved how health care personnel labeled HIV-positive patients. Although disconcerting to patients, some labeling experiences described by participants may have been part of a standard procedure. Terrell described one such situation,

I was in the emergency room and they were taking some blood and I said, "You know, you need to put some gloves on, 'cause I'm HIV positive." The thing was, after that I was admitted to a room and I had signs on my door. 'Biological fluid,' ah, 'caution,' you know? It was terrible. It made me feel really dirty.

Other labeling events, however, appeared more derogatory in nature and designed to belittle HIV-positive patients. Some participants described health care personnel who insisted on labeling patients according to a particular high-risk behavior group, even when the patient is adamant that he doesn't belong to one. Malik described dealing with one such nurse practitioner, stating,

She came in and she's like, "well, how'd you get it?" I said, "I don't know." She asked me about being in the risk categories and I said, "well, I wasn't." And then she said, "no, you're just in denial. You had to have been. You don't 'just get it.' " I'm like, "well, I . . ." I didn't know. I was just thinking, going by those categories, I didn't fit in any of them. It's like, "no, I'm not in any of them." And she's like, "well, yes you are." And I'm like, "no, I'm not." And it became real big confrontation.

Scaring patients. Another set of stigma-related behaviors patients attributed to ignorance or, potentially, cruelty on the part of health care personnel involved scaring patients with issues of mortality. Participants reported a variety of encounters with assorted clinicians in which patients were told their lives were over or that they were lost causes because they were HIVpositive. Noah, for example, recounted how one physician responded in such a way immediately after his diagnosis. He stated, "I was like, 'okay, what's the next step?' And the immunologist just went, 'you're gonna die.' " DeShawn described a similar encounter with a physician who sought him out one evening in his hospital room to seemingly taunt him for his diagnosis. He explained,

\footnotetext{
This little, goofy, bearded guy, says, "You know you gonna die." And he was a doctor. He said, "Do you know what kinda AIDS you got?" I said, "Yeah. I got the AIDS that you can't cure." He said, "Well, you know, you don't got long to live."
}

Mocking patients. In addition to health care personnel scaring patients, participants also described being the targets of outright contempt and ridicule. Participants described these various forms of mockery and contempt as explicit expressions of HIV stigma, which were performed by a host of health care personnel ranging from desk receptionists to attending physicians. Evan provided one such example, in which he explained,

I had a negative thing from a dentist. He was gonna pull a tooth and he gave this sort of smug, superi- 
ority thing about "I've got HIV." A smirk was part of it. He said, "So, how did you catch it?" Now for a lot of people, that's gay sex. That shouldn't be any of his business. The smirk told me as much as his question. Now I can't be sure-I think I got it from an unclean hypodermic needle, but it's none of his business.

Blaming patients. Coupled with these contemptuous episodes, participants described a host of encounters in which health care personnel openly blamed patients for their HIV. Participants described feeling shamed during these episodes, even if they had contracted HIV simply while "living their lives." Cedric described one such encounter with a phlebotomist as follows,

I had one blood draw-she had a hard time drawing my blood. She got really angry and aggravated about it. She kept poking me and I told her it hurt, "It's hurting," you know? And she said, "if you hadn't of done this to yourself, we wouldn't have to be going through this!"

In summary, participants reported being sensitive to health care personnel's demeanor, which patients used to determine other's comfort and attitude toward HIV-positive patients. Nonverbal cues such as proxemics, vocal tones, and eye contact, in particular, were used to infer irritation, anger, nervousness, or discomfort among health care personnel when working with HIV-positive clientele. Participants were especially mindful of shifts in health care personnel's attitudes after their HIV-status was revealed. Similarly, labeling patients and inconsistent or excessive use of safety precautions when working with HIV-positive clientele were each interpreted as indicative of HIV stigma. Although participants reported feeling resentful and unsatisfied after such encounters with health care personnel, they noted that such behaviors did not necessarily impede the delivery of sufficient and effective health care. In other words, they often felt their health care was not compromised, despite the misgivings and stigmatizing demeanors of health care personnel during these encounters. Unfortunately, stigmatizing behaviors exhibited by health care personnel did not always have such benign results, as demonstrated in the following section.

\section{Care provision}

Dealing with fearful and/or demeaning behavior from health care personnel were unpleasant and upsetting experiences for those who endured them; however, participants also described encountering a variety of stigmatizing behaviors that far exceeded funny looks or verbal ridicule and included actions that impaired or even prevented patients' utilization of health care. These encounters ranged from health care personnel ignoring patients or denying services, up to and including the physical abuse of HIVpositive patients. Unlike facets of demeanor, which participants admitted were sometimes ambiguous and potentially attributable to issues other than HIV stigma, events in which health care provision was impaired left little doubt in the minds of those affected that such experiences were rooted in bias and discrimination.

Ignoring patients. One behavior patients felt was rooted in HIV stigma and impaired their health care involved health care personnel ignoring HIV patients, even when patients were in great need. Such events left patients not only in distress, but also angry and resentful of the care they received. Gabriel described one such encounter, in which a physician refused to respond to him, even when being directly addressed.

I was here for a week and there was a doctor who
was attending. He came in my room-he didn't say
a word to me. When I caught his attention, it was
as if I hadn't said anything! Yeah, I felt that was
derogatory about my [HIV] status. I recall that be-
cause it actually prompted me to make a formal
complaint. I went to the patient advocate and ex-
plained what had happened because he was the
doctor, he was outside my door, I needed some-
thing-I was trying to call his attention and he
didn't respond!

Substandard care. Patients also recounted instances in which they received other forms of substandard care, ranging from health care personnel spending inadequate time on a patient's needs to leaving patients in pain to wait upon the care providers' convenience. Jack, who reported a number of such events when seeking dental care, described one such circumstance in which he had consistently been provided inadequate care, despite the fact that he was paying full price for such services. He explained, 
I tell [the hygienist] I'm having problems with one tooth causing pain. The hygienist says, "ok" and 2 months later when I come back in I said, "you know, the pain-it's still there and, if anything, a little worse." She calls the dentist in and the dentist says, "well, you're so hard to anesthetize that we don't, we can't do a thorough cleaning on you. And," he says, "in your condition ... " You know? And I just want to turn and slug him! I'm paying you your regular prices every three months to make sure I don't get cavities and you're telling me you aren't going to anesthetize me because I'm too hard and it really doesn't matter because of my condition?

Not only did Jack experience these events, he saw others deal with similar treatment. As a result, had had come to view HIV stigma and poor quality of care as essentially indistinguishable. He explained,

\begin{abstract}
It's gotten to the point that the last time I was at the clinic, which I was in this week, they had a patient they wanted to pull a tooth for and couldn't get the tooth all the way out. Instead of immediately calling Big University Hospital and getting him in, they told the patient to go home and to come back at 9:00 $\mathrm{AM}$ [the next day] as an emergency patient when the clinic opened. So there is a patient with a tooth halfpulled, in pain, and this is an HIV clinic treating an HIV patient. So is there still a stigma? I consider that a stigma. I try to differentiate stigma and the quality of the medical care that is being given to [us], but I can't differentiate the two anymore. They are so thoroughly entwined that everyone I know kind of expects that, as an HIV person, we're going to get lower quality health care in all areas, but in dental it's extreme.
\end{abstract}

Denied care. At times, participants reported being denied even substandard care because of their HIV-positive status. For instance, some reported encounters in which health care personnel, apparently uncomfortable with HIVpositive clientele, attempted to redirect such patients to alternative sites of care rather than provide any services themselves. For instance, Ahmad explained that after learning he had come in search of HIV services, the care provider with whom he was speaking tried to send him away to clinics in other parts of the city. In particular, he explained, "What she did was start telling me, steering me toward other places to go and ask for the same help that they give, you know?"

Some provision of care or redirection to other helpful services is, at least, better than being fully rejected outright and denied services altogether. For some participants, such as Jack, this occurred due to the inability to find providers willing to take on HIV-positive clients. He explained, "There were years when even my private doctor didn't know of a doctor in the entire city that would treat an [individual with] HIV." Similar accounts were provided by participants, who described both clinical and nonclinical health care personnel refusing to provide services to patients living with HIV. In clinical contexts, for instance, Eric mused, "I've had a couple of incidents where a nurse or a phelmbologist didn't want to draw blood because it was clear to her that she was drawing for a CD4 count." Similarly, he explained,

One time I went to a county hospital to have a tooth pulled. I guess the dentist was a student or an intern or whatever. He refused to do it once he realized I was HIV-positive. They had to send for another doctor.

Clinicians, however, were not the only health care personnel described as refusing to provide services to HIV-positive clientele. Such behaviors also were portrayed by a variety of nonclinicians, such as receptionists, administrative staff, and custodial staff. Evan described one such case, explaining,

I was an inpatient at Big University Hospital and I don't know what they put on the door of the room, but a woman who would normally come in and mop up and sweep, wouldn't. It was really wild, with her shrieking, "I ain't goin' in there!"

Abusive treatment. Perhaps the most blatant and potentially dangerous experiences with stigma reported by participants involved some form of abuse at the hands of health care personnel. Certain abusive events involved malignment, in which health care personnel strategically defamed HIV-positive patients to other health care personnel, potentially ensuring these patients received less favorable treatment from other health care personnel. One such instance was described by David, who explained,

I was treated like garbage. I don't know the lady's name, I could only go and look for her and see her and say, "That's her," but I couldn't say her name because I was so drugged out. She treated me like crap. She called the police on me and said I was abusive. I couldn't even move, but she said I was 
abusive. And she called the floor that I was gonna be admitted to and said that I was abusive, that they'd better watch themselves because I'm being abusive and she doesn't want to get next to me and get scratched, because she may get "the same thing." She didn't think I was listening and she didn't think I understood what she what she meant by that, but I did.

Finally, patients reported acts of physical abuse perpetrated against them by various health care personnel, attributing each of these events to their HIV status. This included patients being pummeled or put into situations in which they were likely to be hurt. David, who had endured malignment by a nurse in a previous encounter, also described being physically mistreated by paramedics. In his own words, he explained,

Being rushed to the hospital a few times I've dealt with paramedics. I'm epileptic, I have seizures. When the paramedics do pick me up, they manhandle me. In other words, they treat me bad . . . Once they ask whoever's called the ambulance that knows my history, who tells 'em I'm HIV-positive, they start thrashing me around. The only part they're careful of is putting in a line in my vein because they don't want to get sick. I mean, the paramedics are cruel and I prefer not to be handled by them at all. Just let me die. If I'm gonna die, let me die, but don't, don't call the ambulance. That's how bad they are.

In summary, participants described a number of stigmatizing experiences at the hands of health care personnel that compromised the quality and effectiveness of the health care patients received. This included ignoring patient needs, providing insufficient and substandard health care to HIV-positive patients, denying and refusing to provide health care services to these patients, and abusing HIV-positive patients, which ranged from malignment to physical abuse. Participants explained that stigmatizing events that impaired the provision of health care could also entail problematic demeanor, such as mocking patients while providing them insufficient services.

\section{DISCUSSION}

In this study, participants reported being both mindful of health care personnel's behav- iors and sensitive to anything that may indicate bias or stigma toward HIV-positive patients. Participants reported encountering what they perceived to be expressions of HIV stigma in a variety of health care environments and performed by a broad range of health care personnel. Such encounters took place in ambulances, doctor's offices, dental care facilities, inpatient hospital rooms, and the common areas of hospitals, such as hallways and reception desks. Problematic behaviors identified as stigmatizing by participants included such things as awkward or nervous nonverbal behaviors, excessive safety precautions, avoidance, refusal to provide care, as well as anger toward and even abuse of HIV-positive patients. These findings extend previous research on HIV stigma in health care settings by (1) focusing on health care personnel's actual behaviors rather than their attitudes and beliefs about HIV-positive patients, (2) including patients' perceptions regarding the behaviors of both clinical and nonclinical health care personnel, and (3) identifying behaviors patients perceive as stigmatizing that are unique to health care contexts.

These results complement and expand upon earlier findings that reveal some health care personnel are reluctant to interact with HIVpositive patients. ${ }^{34,46}$ In some instances, participants reported how this translated into health care personnel's refusal to provide services to HIV-positive patients. This apparent aversion to interacting with individuals who have HIV is especially troubling in light of evidence that being touched and being checked upon signals high quality of care to patients. ${ }^{57,58}$ In fact, egalitarian treatment of patients, regardless of HIV status, has been linked to patients' perceptions of higher quality of care. ${ }^{53}$ Because individuals with HIV wish to be touched, cared for, and treated like any other patients, health care personnel's apprehensiveness could affect patients' confidence in and evaluations of a care provider's competence.

Beyond fearful and aversive behaviors, participants also described feeling disdain, contempt, and even anger directed toward them from various health care personnel. Sensing dislike from care providers has special significance for patients' perceptions of the quality of care they receive, as well as their likeliness to trust or return to their care providers. ${ }^{59-61}$ 
However, patients reported experiencing far more than covert affect, which included events in which health care personnel openly mocked or blamed them for their HIV status, unfairly labeled them or maligned them to other health care personnel, and even physically abused HIV-positive patients. Although violence directed toward people living with HIV has been reported in earlier HIV research, it has almost exclusively been discussed in the context of romantic relationships. ${ }^{17,22}$ These findings reveal a frightening dilemma, in which seeking health care may, in some cases, actually place HIVpositive patients' health and safety at risk. Evidence of events in which health care personnel intentionally jeopardize the well-being of their patients should concern all members of the allied health professions and the appointed stewards of the justice system.

Although such things as nervous nonverbal cues or even physical violence toward people living with HIV may also occur in other social contexts, these behaviors have special significance coming from those upon whom one must depend for health care. Additionally, some of these behaviors are unique to health care contexts, such as care providers using differential or excessive protective gear when working with HIVpositive clientele. Although it may be tempting to dismiss such things as problems of the past, claiming that advances in education on HIV have eradicated these issues, it is noteworthy that participants described such events occurring within weeks or even days of their interviews, making these findings both timely and relevant.

Clinicians such as physicians and nurses should now understand the true risks involved in working with HIV-positive patients and not succumb to irrational fears of contagion; however, participants recounted problematic events occurring with both sets of clinicians within the year preceding the interviews. Although other care providers, such as laboratory technicians, emergency medical technicians, and dentists may not have received sufficient training and education regarding HIV earlier in the epidemic, this should no longer be the case. Yet, participants reported recent problems with these care providers, as well.

Although it may be surprising to find such stigmatizing behaviors among clinicians, perhaps it should not be that participants reported such encounters with non-clinical personnel, such as custodians and administrative staff. These individuals receive little (if any) training on the biomedical aspects of HIV and may rely on knowledge they have acquired about the disease during their daily lives. Given the rampant misinformation and stereotyping of HIV still prevalent in the lay population, encounters with nonclinical personnel who are reluctant to interact with or even clean the rooms of HIV patients may be a more common problem than is currently realized. These findings suggest that additional outreach and continuing education is required among health care providers and other personnel not only regarding HIV, but also regarding the impact of their behaviors on patients. Behaviors identified in this study as problematic from patients' perspectives should be avoided or, when a necessary component of care, further explained by health care personnel, as they may be interpreted as discriminatory or stigmatizing by patients with HIV. These dialogues can help foster the image that health care personnel are knowledgeable about the disease and want to provide patients with the best care possible. Failing to do so may not only impair provider-patient relations, but could conceivably even lead patients to avoid health care in the future. Without modifying these behaviors, the likelihood of legal action taken against care providers and the facilities in which they are employed may increase, given the correlation between law suits and patients who are dissatisfied with or take offense to their care providers. ${ }^{54}$ This is especially important given how HIV-positive patients may sometimes identify innocent or unintentional actions as stigmatizing, given their hypersensitivity to social stigma. ${ }^{46,47}$ Such sensitivity may be particularly acute following physical changes endemic to prolonged use of antiretroviral therapies, which combat the virus but mar the body (e.g., lipodystophy). ${ }^{62,63}$

This study raises important questions about both the perception and prevalence of stigmatizing behaviors in health care contexts in general, but in certain contexts, in particular. For instance, HIV stigma in the practice of dentistry has received little attention in the research literature, but was the source of considerable frustration and anxiety for a variety of participants in this study. Understanding of this prob- 
lem can be enhanced by research that explores dentists' perceptions of HIV, its etiology, and transmission. Also, additional research must focus on these problems among other health care personnel that have, to date, received little to no attention in the HIV stigma literature. Such research could also couple attitudes or behavioral intentions of health care personnel with their actual performance, rather than just concentrating solely on the antecedents to stigmatizing behaviors or the behaviors, themselves. Such research may even explore distinctions between provider perceptions of encounters and the perceptions of their patients, in order to identify discrepancies in what providers and patients consider appropriate or stigmatizing.

Although identification of problematic behaviors is an important step in disarming the heightened sensitivity and anxiety patients may have about being stigmatized, knowing what behaviors send positive, reassuring signals to HIV-positive patients is of equal significance. Identification and performance of these more positive behaviors has the potential to further enhance care providers' work and inspire patients' confidence in the care they receive. Therefore, future research should explore forms of proactive behaviors health care personnel can employ to generate this amity. Finally, this study raises questions regarding the role of stigma in the health care provision of other illnesses. All illness is stigmatized, though the reasons for and degree of stigmatization differ depending upon illness context. ${ }^{64,65}$ As such, research efforts should focus on better identifying the forms and functions of stigmatizing behaviors among health care personnel attending to people living with other highly stigmatized illnesses.

In evaluating our findings, several limitations to our study should be acknowledged. To begin, the methods used in this study are excellent for identifying the forms and functions of stigma experienced by HIV-positive patients in health care settings, but are unable to explain the frequency of these experiences or the magnitude of their effects on patient outcomes, such as health care satisfaction and likelihood of future health care utilization. In addition, this study was based on interviews with a sample of only 50 participants, all of whom were male and currently seeking treatment through VA hospitals. The fact that the sample was entirely male is particularly important, as men may be subjected to some forms of stigma that differ from those experienced by women living with HIV. The fact the participants were all veterans, most of whom are older and have dealt with HIV/AIDS for many years, also has implications for our results. Younger people with HIV or nonveterans may encounter different experiences with stigma or access different health care facilities than those described by the current study participants. Of note, however, is the fact that participants' health care histories did include a wide variety of health care facilities outside of the VA, which strengthens the significance and applicability of these findings for nongovernmental health care organizations. In order to address these limitations and to provide a more accurate assessment of the forms, frequencies, and effects of patient perceived stigma among health care personnel, larger studies are currently being conducted utilizing structured interviews with significant numbers of participants spread across multiple states.

\section{CONCLUSION}

Participants described a variety of behaviors performed by health care personnel that they perceived to be indicative of HIV stigma, ranging from ambiguous nonverbal cues, such as minimal eye contact, to blatant discrimination, such as physical abuse of HIV-positive patients. These findings offer health care personnel a tangible list of behaviors that should be either avoided or further explained to HIV-positive patients, as they may be interpreted as stigmatizing. Also, this study reveals that patients are sensitive to such behaviors being performed by a variety of health care personnel, indicating the need for all such personnel to be mindful of their actions toward these patients. Further research is needed to identify the prevalence of such behaviors and their effects on HIV-positive patients.

\section{ACKNOWLEDGMENTS}

This research was supported by a Veterans Administration Health Services Research and Development training grant through the Cen- 
ter for Management of Complex Chronic Care (TPP 42-002; HSP LIP 42-513). The authors would like to thank Carrie Jordan for her assistance early in the project. The authors also extend their sincerest gratitude to Jonessa Farano, NP, both for her efforts assisting with this project and for the exceptional care she provides veterans living with HIV. Lastly, the authors would like to thank the study participants for the time, experience, and insight they offered us in this project.

\section{REFERENCES}

1. Glynn M, Rhodes P. Estimated HIV prevalence in the United States at the end of 2003. National HIV Prevention Conference, Atlanta, GA: June 2005.

2. Pearlin LI, Aneshensel CS, LeBlanc AJ. The forms and mechanisms of stress proliferation: The care of AIDS caregivers. J Health Soc Behav 1997;38:223-236.

3. Wood E, Hogg RS, Yip B, et al. Effect of medication adherence on survival of HIV-infected adults who start highly active antiretroviral therapy when the $\mathrm{CD}^{+}{ }^{+}$cell count is 0.200 to $0.350 \times 10^{9}$ cells/L. Ann Intern Med 2003;39:810-816.

4. Botnick MR. Part 1: HIV as 'The line in the sand.' J Homosex 2000;39:39-76.

5. Herek GM, Capitanio JP, Widaman KF. HIV-related stigma and knowledge in the United States: Prevalence and trends, 1991-1999. Am J Public Health 2002;92:371-377.

6. Herek GM, Capitanio JP. AIDS stigma and sexual prejudice. Am Behav Sci 1999;42:1130-1147.

7. Bennett MJ. Stigmatization: Experiences of persons with acquired immune deficiency syndrome. Issues Ment Health Nurs 1990;11:141-154.

8. Gostin LO. The AIDS Litigation Project. A national review of court and human rights commission decisions, Part I: The social impact of AIDS. JAMA 1990; 263:1961-1970.

9. Herek GM, Capitanio JP. Public reactions to AIDS in the United Stated: A second decade of stigma. Am J Public Health 1993;83:574-577.

10. Herek GM, Capitanio JP. Conspiracies, contagion, and compassion: Trust and public reactions to AIDS. AIDS Educ Prev 1994;6:365-375.

11. Herek GM, Capitanio JP. AIDS stigma and contact with persons with AIDS: Effects of direct and vicarious contact. J Appl Soc Psychol 1997;27:1-36.

12. Herek GM, Glunt EK. An epidemic of stigma: Public reactions to AIDS. Am Psychol 1988;43:886-891.

13. Price V, Hsu M. Public opinion about AIDS policies: The role of misinformation and attitudes toward homosexuals. Public Opin Q 1992;56:29-52.

14. Gielen AC, O'Campo P, Faden RR., Eke A. Women's disclosure of HIV status: experiences of mistreatment and violence in an urban setting. Women Health 1997;25:19-31.
15. Hunter ND, Rubenstein WB. AIDS and civil rights: The new agenda. AIDS Public Policy J 1992;7:204208.

16. Zierler S, Cunningham WE, Andersen R, et al. Violence victimization after HIV infection in a US probability sample of adult patients in primary care. Am J Public Health 2000;90:208-215.

17. Craft SM, Serovich JM. Family-of-origin factors and partner violence in the intimate relationships of gay men who are HIV positive. J Interpers Violence 2005;20:777-791.

18. D'Augelli AR. AIDS fears and homophobia among rural nursing personnel. AIDS Educ Prev 1989;1: 277-284.

19. Derlega VJ, Lovejoy D, Winstead BA. Personal accounts on disclosing and concealing HIV-positive test results: Weighing the benefits and risks. In: Derlega VJ, Barbee AP, eds. HIV and Social Interaction. Thousand Oaks, CA: Sage, 1998:147-164.

20. Goldin CS. Stigmatization and AIDS: critical issues in public health. Soc Sci Med 1994;39:1359-1366.

21. Heckman TG, Somlai AM, Kalichman SC, Franzoi SL, Kelly JA. Psychosocial differences between urban and rural people living with HIV/AIDS. J Rural Health 1998;14:138-145.

22. Liebschutz JM, Geier JL, Horton NJ, Chuang $\mathrm{CH}$, Samet JH. Physical and sexual violence and health care utilization in HIV-infected persons with alcohol problems. AIDS Care 2005;17:566-578.

23. Marzuk PM, Tierney $H$, Tardiff $K$, et al. Increased risk of suicide in persons with AIDS. JAMA 1988;259: 1333-1337.

24. Chesney MA, Smith AW. Critical delays in HIV testing and care: The potential role of stigma. Am Behav Sci 1999;42:1162-1174.

25. Gaudioso A. An investigation of misrepresented HIV status between sexual contacts. Dissertation Abstracts International, A66(1-A). University Microfilms International, 2005.

26. Ford K, Wirawan DN, Sumantera GM, Sawitri AA, Stahre M. Voluntary HIV testing, disclosure, and stigma among injection drug users in Bali, Indonesia. AIDS Educ Prev 2004;16:487-498.

27. Golin C, Isasi F, Bontempi JB, Eng E. Secret pills: HIVpositive patients' experiences taking antiretroviral therapy in North Carolina. AIDS Educ Prev 2002;14: 318-329.

28. Rintamaki LS, Wolf MS, Davis TC, Skripkauskas S, Bennett CL. Social stigma and HIV medication adherence. AIDS Patient Care STDs 2006;20:359-368.

29. Rintamaki LS, Hogan TP, Weaver FM. Social stigma and the medication practices of U.S. military veterans living with HIV. Presented at the International Conference on Communication in Healthcare. Chicago, IL: October, 2005.

30. Crandall CS, Coleman R. AIDS-related stigmatization and the disruption of social relationships. J Soc Pers Relat 1992;9:163-177.

31. Chung JY, Magraw MM. A group approach to psychosocial issues faced by HIV-positive women. Hosp Commun Psychiatry 1992;43;891-894. 
32. Moneyham L, Seals B, Demi A, et al. Perceptions of stigma in women infected with HIV. AIDS Patient Care STDs 1996;10:162-167.

33. McCann TV. Willingness to provide care and treatment for patients with HIV/AIDS. J Adv Nurs 1997; 25:1033-1039.

34. McCann TV. Reluctance amongst nurses and doctors to care for and treat patients with HIV/AIDS. AIDS Care 1999;11:355-359.

35. Norton R, Schwartzbaum J, Wheat J. Language discrimination of general physicians: AIDS metaphors used in the AIDS crisis. Commun Res 1990;17:809-826.

36. Breault AJ, Polifroni EC. Caring for people with AIDS: Nurses' attitudes and feelings. J Adv Nurs 1992;17: 21-27.

37. Dworkin J, Albrecht G, Cooksey J. Concern about AIDS among hospital physicians, nurses and social workers. Soc Sci Med 1991;33:239-248.

38. Knox MD, Dow MG, Cotton DA. Mental health care providers: The need for AIDS education. AIDS Educ Prev 1989;1:285-290.

39. Ficarrotto TJ, Grade M, Zegans LS. Occupational and personal risk estimates for HIV contagion among incoming graduate nursing students. J Assoc Nurs AIDS Care 1991;2:5-11.

40. Orlander JD, Samet JH, Kazis L, Freedberg KA, Libman H. Improving medical residents' attitudes toward HIV-infected persons through training in an HIV staging and triage clinic. Acad Med 1994;69: 1001-1003.

41. Crawford I, Humfleet G, Ribordy SC, Ho FC, Vickers A. Stigmatization of AIDS patients by mental health professionals. Prof Psychol Res Pract 1991;22:357-361.

42. Kass NE, Faden RR, Fox R, Dudley J. Homosexual and bisexual men's perceptions of discrimination in health services. Am J Public Health 1992;82:1277-1279.

43. Levin BW, Krantz DH, Driscoll JM, Fleischman AR. The treatment of non-HIV-related conditions in newborns at risk for HIV: A survey of neonatologists. Am J Public Health 1995;85:1507-1513.

44. Quam MD. The sick role, stigma, and pollution: The case of AIDS. In: Feldman DA, ed. Culture and AIDS. New York: Praeger, 1990:29-44.

45. Eagly AH, Chaiken S. The Psychology of Attitudes. Orlando, FL: Harcourt Brace Jovanovich College Publishers, 1993.

46. Chapman E. Patient impact of negative representations of HIV. AIDS Patient Care STDs 2002;16:173177.

47. Frable DE, Blackstone T, Scherbaum C. Marginal and mindful: Deviants in social interactions. J Pers Soc Psychol 1990;59:140-149.

48. Crocker J, Major B. Social stigma and self-esteem: The self-protective properties of stigma. Psychol Rev 1989;96:608-630.

49. Crocker J, Voelkl K, Testa M, Major B. Social stigma: The affective consequences of attributional ambiguity. J Pers Soc Psychol 1991;60:218-228.

50. Major B, Crocker J. Social stigma: The affective consequences of attributional ambiguity. In: Mackie DM,
Hamilton DL, eds. Affect, Cognition, and Stereotyping: Interactive Processes in Intergroup Perception. New York: Academic Press, 1993:345-370.

51. Pleck JH, O'Donnell L, O'Donnell C, Snarey J. AIDSphobia, contact with AIDS, and AIDS-related job stress in hospital workers. J Homosex 1988;15:41-54.

52. Parker R, Aggleton P. HIV and AIDS-related stigma and discrimination: A conceptual framework and implications for action. Soc Sci Med 2003;57:13-24.

53. Surlis S, Hyde A. HIV-positive patients' experiences of stigma during hospitalization. J Assoc Nurs in AIDS Care 2001;12:68-77.

54. Levinson W, Roter DL, Mullooly JP, Dull VT, Frankel RM. Physician-patient communication: The relationship with malpractice claims among primary care physicians and surgeons. JAMA 1997;277:553-559.

55. Charmaz K. Qualitative interviewing and grounded theory analysis. In: Gubrium JF, Holstein JA, eds. Handbook of Interview Research: Context and Method. Thousand Oaks, CA: Sage, 2002:675-694

56. Strauss AL, Corbin J. Basics of Qualitative Research: Grounded Theory Procedures and Techniques. Newbury Park, CA: Sage, 1990.

57. Kermode M. Patients' experiences of nursing interventions during hospitalisation with an AIDS-defining illness. Aust J Adv Nurs 1995;12:20-30.

58. Cederfjall C, Wredling R. The expressed needs of a group of HIV-infected gay men subsequent to hospital care. J Assoc Nurses AIDS Care 1999;10:66-74.

59. Topacoglu H, Karcioglu O, Ozucelik N, et al. Analysis of factors affecting satisfaction in the emergency department: A survey of 1019 patients. Adv Ther 2004;21:380-388.

60. Fiscella K, Meldrum S, Franks P, et al. Patient trust: Is it related to patient-centered behavior of primary care physicians? Med Care 2004;42:1049-1055.

61. Rowland PA, Coe NP, Burchard KW, Pricolo VE. Factors affecting the professional image of physicians. Curr Surg 2005;62:214-219.

62. Huang JS, Lee D, Becerra K, et al. Body image in Men with HIV. AIDS Patient Care STDs 2006;20:668-677.

63. Steel JL, Landsittel D, Calhoun B, et al. Effects of lipodystrophy on quality of life and depression in HIV-infected men on HAART. AIDS Patient Care STDs 2006;20:565-575.

64. Parsons T. The Social System. Glencoe, IL: Free Press, 1951.

65. Vash CL. The Psychology of Disability. New York: Springer, 1981.

Address reprint requests to: Lance S. Rintamaki

Department of Communication and Health Behavior

The State University of New York at Buffalo 325 Baldy Hall Buffalo, NY 14260

E-mail: rlance@buffalo.edu 
Copyright of AIDS Patient Care \& STDs is the property of Mary Ann Liebert, Inc. and its content may not be copied or emailed to multiple sites or posted to a listserv without the copyright holder's express written permission. However, users may print, download, or email articles for individual use. 